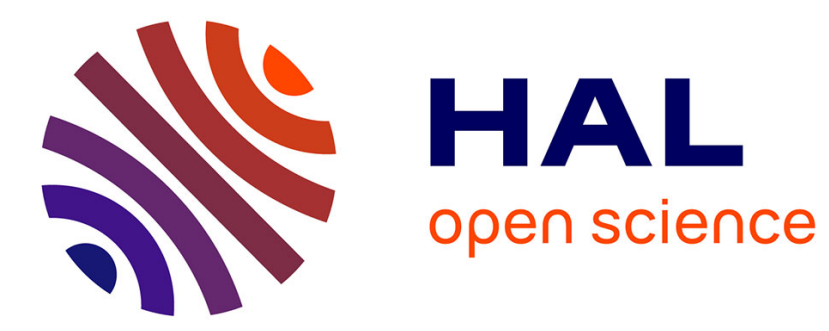

\title{
The elastic modulii of evaporated C60 films
}

\author{
H. Coufal, K. Meyer, R. Grygier, M. de Vries, D. Jenrich, P. Hess
}

\section{To cite this version:}

H. Coufal, K. Meyer, R. Grygier, M. de Vries, D. Jenrich, et al.. The elastic modulii of evaporated C60 films. Journal de Physique IV Proceedings, 1994, 04 (C7), pp.C7-717-C7-720. 10.1051/jp4:19947168 . jpa-00253228

\section{HAL Id: jpa-00253228 https://hal.science/jpa-00253228}

Submitted on 1 Jan 1994

HAL is a multi-disciplinary open access archive for the deposit and dissemination of scientific research documents, whether they are published or not. The documents may come from teaching and research institutions in France or abroad, or from public or private research centers.
L'archive ouverte pluridisciplinaire HAL, est destinée au dépôt et à la diffusion de documents scientifiques de niveau recherche, publiés ou non, émanant des établissements d'enseignement et de recherche français ou étrangers, des laboratoires publics ou privés. 


\title{
The elastic modulii of evaporated C60 films
}

\author{
H. Coufal, K. Meyer, R.K. Grygier, M. de Vries, D. Jenrich* and P. Hess* \\ IBM Research Division, Almaden Research Center, 650 Harry Road, San Jose, California 95120-6099, \\ U.S.A. \\ * Institute of Physical Chemistry, University of Heidelberg, Im Neuenheimer Feld 253, 69120 Heidelberg, \\ Germany
}

\begin{abstract}
Surface acoustic wave (SAW) pulses were excited in C60 films on a variety of substrates using pulses from Excimer lasers for excitation. An optical beam deflection technique and polymer electret transducers were utilized to detect the propagation of the SAW pulse with high spatial and temporal resolution, allowing an accuracy of better than $0.1 \%$ for SAW velocity measurements. With this technique the frequency dependence of the SAW velocity was determined for fullerite films and density, as well as elastic modulii of the films were derived by a theoretical analysis of the dispersion effect.
\end{abstract}

\section{INTRODUCTION}

The availability of $\mathrm{C} 60$ as single crystals and thin films has stimulated the interest in the physical properties of this new class of van-der-Waals solid [1]. In addition to the well studied optical and electrical properties the mechanical properties are of fundamental interest for the understanding of the lattice dynamics of solid $C 60$ (fullerite) materials [2-5]. Due to limited quantities of material many of the classical mechanical methods are difficult to apply or provide results with limited accuracy. For studies of the mechanical properties of thin films on a substrate surface acoustic waves (SAW) are the idcal tool [6]. In these waves the elastic energy is confined at the surface of the sample to a depth of approximately one wavelength.

\section{EXPERIMENT}

In the present experiments SAW pulses were excited in the C60) films by focussing an excimer laser pulse to a narrow line. According to micrographs of ablated samples the focus was about $10-20 \mathrm{~mm}$ long and $20-30 \mu \mathrm{m}$ wide. For pulse encrgies below $<500 \mu \mathrm{J}$, normally employed in these experiments, the acoustic pulses werc generated predominantly by a thermoelastic mechanism, whereas at higher pulse energies ablation of the strongly absorbing $\mathrm{C} 60$ film was observed and contributed to signal generation.

Detection of SAW was accomplished by two different techniques. The first one used a piezoelectric polymer film that was pressed against the sample under study by a knife edge with a width of approximately $45 \mu \mathrm{m}$ resulting in a bandwidth of approximately $150 \mathrm{MHz}$ [7]. To take full advantage of the high bandwidth that laser generation of SAW affords, an optical probe technique has been developed [8]. The bandwidth of the optical detection system is $1 \mathrm{GHz}$ and SAW rise times shorter than 1 ns were observed. 
The velocity of SAWs was measured by determining the propagation time of the transient acoustic pulses along the surface for different distances between excitation laser line focus and detector. The experiments were performed on well characterized substrates: the (001) and (111) planes of silicon for different propagation directions and on fused quartz substrates (Suprasil).

Fullerite films of thicknesses between $860 \mathrm{~nm}$ and $1300 \mathrm{~nm}$ were deposited on these substrates in a thermal evaporator. SAW velocities were measured immediately after deposition and for an extended period of time after the deposition. Despite the fact that the optical appearance of the $\mathrm{C} 60$ film changed in the first hour after the deposition no change in the elastic properties was detectable, even after wceks.

\section{DISCUSSION}

From the observed time dependent SAW signals, a typical signal is shown in Fig. 1, velocity and attenuation are derived by Fourier analysis of signals measured at different distances away from the source. The frequency dependence of the phase velocity (Fig. 2), also known as "dispersion effect," was fitted with the Thiersten model [9] to determine the density and the elastic constants of the film material. The parametcrs for the fit that is shown in Fig. 2 together with the experimental result are summarized in Table 1 and compared with literature values for freestanding films and crystals of C60.

Our experiments provide an accurate value of the density. Within experimental error this density value is identical to that of C60 single crystals. This is rather unexpected, since evaporated films typically have densities well below bulk samples of the same material due to numerous lattice defects in the film. One explanation for this surprisingly high density of the C60 films would be that the reported densities of $\mathrm{C} 60$ ) single crystals might be too low due to a small amount of low density solvent, that is used during crystal growth, being trapped in the crystal. The mechanical properties, e.g. the bulk modulus, are similar to those of Graphite [3]. This is to be expected since van-der-Waals interaction is dominant between the individual molecular units of these two carbon alotrops

The Young's modulus obtained for our fullerite films is with 12 GPa considerably smaller than the value recently reported for $\mathrm{C} 60$ crystals $(15.9 \mathrm{GPa})$ [4]. Using our value for the Poisson's ratio a Young's modulus of $45.4 \mathrm{GPa}$ and $81.7 \mathrm{GPa}$, respectively, can be derived from recent experiments on two free standing C.60 films [5]. These rather large differences indicate that the Young's modulus of C60 samples depends critically on the sample preparation technique. Differences could be duc to distortions and lattice defects in the structure of the films. It was also found that small concentrations of $(70$ ) lecrease the clastic moduli of the film substantially. Trapped solvent molecules would have the same effect. These explanations can be ruled out, however, for our samples due to the purity of the $\mathrm{C} 60$ material and the deposition conditions.

Two values have been reported for the bulk modulus of $\mathrm{C} 60$ crystals namely $14.4 \mathrm{GPa}$ [2] and $18.1 \mathrm{GPa}[3]$. Both values are considerably larger than our result of $6.4 \mathrm{GPa}$ for fullerite films. This highlights, the fact that the fullerite films that were prepared at deposition rates of the order of several $\mathrm{nm} / \mathrm{min}$ are substantially softer than the single crystals due to their disordered structure. These data indicate that the mechanical properties of fullerite films depend very much on the sample preparation conditions. 


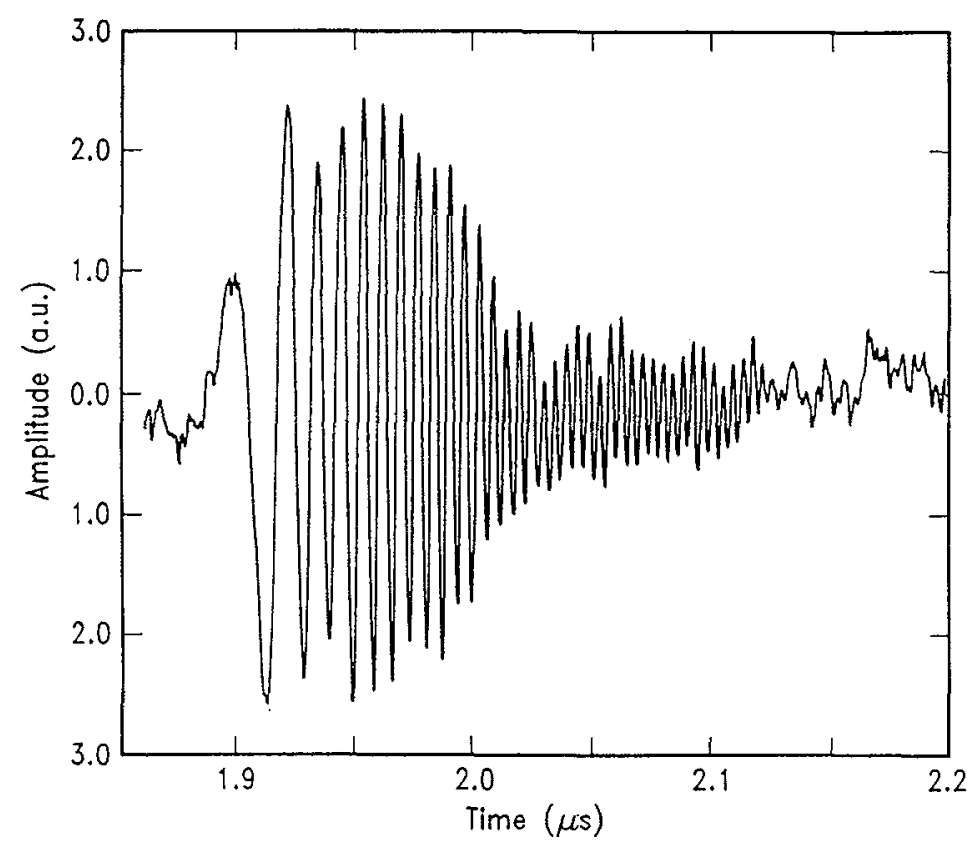

Figure 1. Typical SAW signal for a $830 \mathrm{~nm}$ thick fullerite film on a Si (111) substrate. The SAW pulse is propagating along the $\langle 112\rangle$ direction of the Si substrate and is detected $9 \mathrm{~mm}$ away from the focus of the cxcimer laser with optical beam deflection.

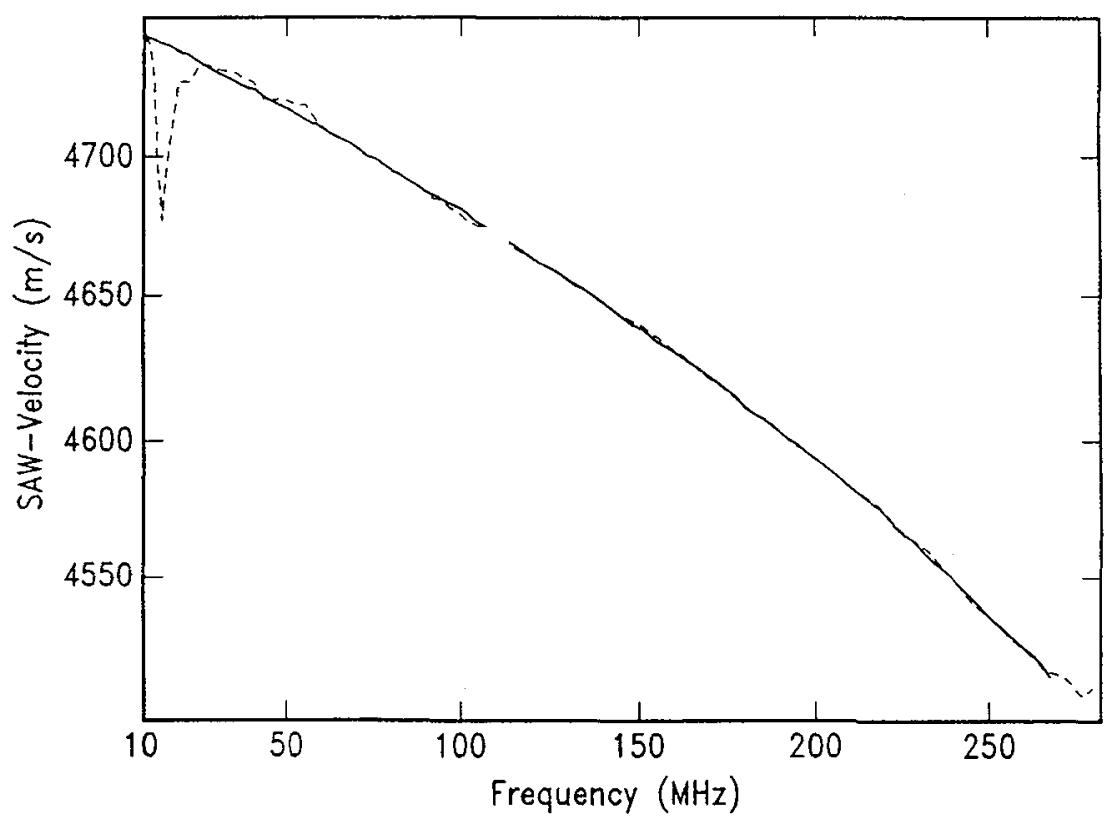

Figure 2. Frequency depcndence of the SAW phase velocity of the film shown in Fig. 1: experimental data; ---- numcrical fit bascd on the parameters of Tab. 1. 


\begin{tabular}{|c|c|c|c|c|}
\hline & \multicolumn{2}{|c|}{ Cor Film } & \multirow[t]{2}{*}{$\mathrm{C}_{60}$ Crystal } & \multirow[t]{2}{*}{ Units } \\
\hline & $\begin{array}{l}\text { On Substrate } \\
\text { [Present Work] }\end{array}$ & Irreestanding & & \\
\hline Density, $\rho$ & $1660 \pm 10$ & & $1672[3]$ & $\mathrm{Kg} / \mathrm{m}^{3}$ \\
\hline Young's Morlulus, E & $12 \pm 1$ & $\begin{array}{l}45.4[5] \\
81.7[5]\end{array}$ & $15.9[4]$ & $\mathrm{GPa}$ \\
\hline Bulk Modulus, K & $6.4 \pm 0.5$ & & $\begin{array}{l}14.4[2] \\
18.1[3]\end{array}$ & $\mathrm{GPa}$ \\
\hline Poisson's Ratio, v & $0.18+0.194$ & & & \\
\hline $\begin{array}{l}\text { Velocity of Sound, Transverse, } v_{t} \\
\text { Velocity of Sound, Logitudinal, } v_{t}\end{array}$ & $\begin{array}{l}1750 \pm(60 \\
2820 \pm 801\end{array}$ & & & $\mathrm{~m} / \mathrm{s}$ \\
\hline $\mathrm{E} /(\mathrm{I}-v)$ & $14.6 \pm 2$ & $\begin{array}{l}5.4[5] \\
99.6[5]\end{array}$ & & $\mathrm{GPa}$ \\
\hline
\end{tabular}

Table 1. The elastic properties of $\mathrm{C} 60$ films and crystals.

\section{REFERENCES}

1. Krätschmer W., Lamb L. D., Fostiropoulos K, and Huffman D. R., Nature 347 (1990) 3.54.

2. Fisher J. E.,Heincy P., McGic A.,Romanow W. J., Denenstein A. M., McCaulcy J. F. and Smith A. B., Srience 252 (1991) 1288.

3. Duclos S. J., Brister K., Haddon R. C., Kortan A. R. and Thicl A., Nature 351 (1991) 380.

4. Shi X. D., Kortan A. R., Williams J. M., Kini A. M. Savall B. M. and Chaikin P. M., Phys. Rev. Lett. 68 (1992) 827.

5. Eom C. B., Hebard A. F., Trimble L. E., Coller G. K. and Haddon R. C., Science 259 (1993) 1887.

6. Neubrand A. and Hcss P., J. Appl. Phys. 71 (1992) 227.

7. Coufal H., Grygier R. K., Hess P. and Neubrand A., J. Acoust. Soc. Am. 92 (1992) 2980.

8. Coufal H., Meyer K., Grygier R. K., Hess P. and Ncubrand A., J. Acoust. Soc. Am., to be published.

9. Thiersten H. F., J. Appl. Phys. 40 (1968) 770. 